\title{
Media exposure during infancy and early childhood: the effects of content and context on learning and development
}

\section{Srividya Ramasubramanian}

To cite this article: Srividya Ramasubramanian (2017): Media exposure during infancy and early childhood: the effects of content and context on learning and development, Journal of Children and Media, DOI: $10.1080 / 17482798.2017 .1375216$

To link to this article: http://dx.doi.org/10.1080/17482798.2017.1375216

Published online: 11 Sep 2017.

Submit your article to this journal $\llbracket$

Џ Article views: 69

Q View related articles 두

View Crossmark data $\nearrow$ 
BOOK REVIEW

\section{Media exposure during infancy and early childhood: the effects of content and context on learning and development, edited by Rachel Barr and Deborah Nichols Linebarger, Cham, Springer, 2017, 303 pp., \$79.00 (ebook), ISBN 978-3-319-45102-2; \$99.99 (hardcover), ISBN 978-3-319-45100-8}

Right after the book Media Exposure during Infancy and Early Childhood arrived in my mailbox this summer, my cousin visited us over a weekend. After reading the book's title, he said, "I'm sure the research clearly shows how awful it is for kids to use media devices at a very young age. That's why we have a no-media policy in our home." I laughed and explained that with every new wave of media technology, parents typically experience either moral panic or extreme optimism about the emerging media. However, the research on this topic is much more nuanced than recommending an all-or-none media approach. I further explained that this book in fact provides ample evidence for how content and context should be taken into consideration in understanding how media exposure shapes young children.

Barr and Linebarger's book addresses important questions such as "How, whether, where, and when do children learn from media," "What type of content is educational?" and "When to share devices versus when to enable independence?"These questions are examined across a range of media formats such as television, e-books, educational apps, touchscreen devices, video chats, and mobile devices. In what the editors refer to as "the new blooming, buzzing confusion," the complex contemporary media landscape can be challenging to navigate, especially for parents of young kids. The marketplace is flooded with an explosive array of baby media with claims of enhancing learning. There is often a big gap between the introduction of technologies and resulting published research on their effectiveness. As a result, very little is known about whether these new technologies and programming are developmentally appropriate or are effective in increasing children's learning. Under these circumstances, it is very important for research on children and media to go beyond simple cause-effect relationships to exploring differential effects based on content and context.

In this edited volume, the authors examine multiple variables that influence effects of media on infants and toddlers across nine scholarly chapters and their accompanying commentaries. Taking an integrative theoretical approach to developmental outcomes of media exposure, the chapters in this book emphasize three main factors: (a) child-oriented factors such as age, gender, disability status, memory, and cognitive constraints; (b) content-related attributes such as storyline, character development, formal features, media platforms, and interactivity, and, (c) contextual factors such as parent availability, parent-child relationship, home environment, and linguistic preferences. The nine scholarly chapters focus on home-school environmental contexts, learning from touchscreen devices versus TV, online processing within interactive and non-interactive contexts, conceptualizing educational programming, parasocial relationships, parent-child interactions, parental media mediation, family relationships in online video chats, and educational apps.

As someone committed to building meaningful cross-sector partnerships relating to media and children, it was refreshing to note that both scholars and practitioners contributed as authors to the book. The editors are well-respected experts in developmental media psychology with a strong record of applying basic scientific research into real-world contexts through early intervention programs and evaluation research on several media products. What was most interesting 
and unique about this book is this idea of including "commentary" chapters by content creators, media producers, and practitioners. As each topic was introduced, we first read an in-depth, rigorous, and comprehensive scholarly overview of the current state of literature. These chapters were penned by well-established developmental media scholars such as Ellen Wartella, Daniel Anderson, Jessica Taylor Piotrowski, and Kathy Hirsch-Pasek, in addition to up-and-coming scholars in the field. Each scholarly chapter is then followed by a hands-on, applied commentary that takes the scholarly research and places it within the context of creating media content for children. Practitioners who wrote the commentaries were media strategists, researchers, creative artists, and educators at organizations such as Sesame Workshop, PBS KIDS, PlayScience, Pittsburgh Public Schools, Fred Rogers Center, and Common Sense Media.

Maybe because I personally enjoy video chats with family members across the world, I thoroughly enjoyed Chapter 16 (by Elisabeth McClure and Rachel Barr) and the commentary chapter that went with it (by Rosemarie T. Truglio and Jennifer Kotler from Sesame Workshop). Specifically, I liked that the scholarly chapter referenced Just Beginning and United through Reading, which were later explored in greater depth in the commentary chapter. Additionally, the inclusion of verbatim quotes from family conversations made the chapter more accessible and relatable. Chapter 9 on parasocial relationships of children with media characters (by Melissa Richards and Sandra L. Calvert) and the commentary to this chapter (by Linda Simensky from PBS KIDS) fit fantastically well with one another. Similarly, another favorite chapter pairing for me was on educational apps and the science of learning (by Jennifer M. Zosh, Sarah Roseberry Lytle, Roberta Michnick Golinkoff, and Kathy Hirsch-Pasek) and the accompanying commentary chapter (by Jeremy Boyle and Melissa Butler from Fred Rogers Center and the Pittsburgh Public Schools, respectively). It was excellent to see exactly how ideas such as "minds-on" learning, meaningfulness, and engagement were applied to the Children's Innovation Project in this commentary. However, one drawback of the volume was that there was little consistency in length, quality, or structure across chapters. Not all chapter pairs fit perfectly well with one another, especially when the commentaries tended to summarize the scholarly chapter without going into the application of the research in their own spheres of work beyond traditional academe.

It would have been nice to push this back-and-forth "conversation" across the scholarly chapters and the commentaries a bit further. Perhaps scholars and practitioners could have co-authored chapters together where the research and practice could be seamlessly interwoven into the narrative. Hopefully one of the takeaways from the book is a better understanding for the reader about how important it is for professionals in the media industry to use theory-driven, evidence-based research in designing their content. Similarly, the questions and concluding thoughts by the practitioners at the end of their commentaries invite scholars to further investigate these questions in future research. I wish we had more platforms and forums such as this book for facilitating continued conversations among scholars, media producers, policy-makers, K-12 teachers, and community-based youth organizations who care deeply about providing high-quality media content for young children.

Overall, Media Exposure during Infancy and Early Childhood is an excellent resource for those interested in cutting-edge research on developmental psychology, educational media, and applied media interventions for young children. It also provides much-needed guidance to caregivers of young children about whether and what media are appropriate to use under which situations. And hopefully, it will convince my cousin to reconsider his no-media policy for his little ones. 